\title{
Decreased MMP1 gene expression in acute myeloid leukaemia
}

\author{
Jacek Pietrzak ${ }^{1}$ (D) Marek Mirowski ${ }^{1} \cdot$ Agnieszka Jeleń $^{1} \cdot$ Rafał Świechowski - Damian Wodziński ${ }^{1}$. \\ Katarzyna Niebudek ${ }^{1} \cdot$ Ewa Balcerczak $^{1}$
}

Received: 17 December 2018 / Accepted: 7 February 2019 / Published online: 12 February 2019

(c) The Author(s) 2019

\begin{abstract}
Acute myeloid leukaemia (AML) is a heterogeneous disorder of haematopoietic stem cells or progenitor cells. Metalloproteinases (MMPs) are proteolytic enzymes whose activity is increased in different types of solid tumours. These enzymes regulate many processes associated with tumour progression. In haematological malignancy, the role of MMPs seems to be underestimated, and only metalloproteinase 2 (MMP2) and metalloproteinase 9 (MMP9) have been widely examined so far. In this work, differences in metalloproteinase 1 (MMP1) gene expression between patients with AML and healthy individuals were assessed. The relative expression level of the MMP1 gene was obtained by a real time PCR method preceded by reverse transcription. The relative level of $M M P 1$ gene expression in patients with AML was decreased when compared to that of the control group. The role of MMP1 in AML could be different from that in solid tumours. Decreased MMP1 gene expression in AML similar to that of MMP9, shows a greater role for MMP1 in normal haematopoiesis than in the development of leukaemic cells.
\end{abstract}

Keywords Acute myeloid leukaemia $\cdot$ MMP1 $\cdot$ Real time PCR $\cdot M M P 1$ gene expression

\section{Introduction}

Acute myeloid leukaemia (AML) is a manifold disease, characterized by the clonal development of primitive forms of haematopoietic cells and their inability to correctly differentiate and respond to the regulators of proliferation [1].

The WHO classification of AML is based on cytogenetic and molecular genetic changes occurring in cancer cells.

Leukaemic clones develop as a result of transformation of haematopoietic stem cells or progenitor cells [2]. Mutations in leukaemic cells belong to two subgroups, the first of which includes mutations in genes responsible for cell proliferation or survival (FLT3, RAS, PTPN11, TEL/PDGFbR) $[3,4]$. The second group of mutations is created by changes in genes related to apoptosis and differentiation (AML/ETO, $P M L / R A R \alpha, C E B P A, C B F, H O X, C B P / P 300)$ [3].

Jacek Pietrzak

jacek.pietrzak@umed.lodz.pl

1 Laboratory of Molecular Diagnostics and Pharmacogenomics, Department of Pharmaceutical Biochemistry and Molecular Diagnostics, Medical University of Lodz, Muszynskiego 1, 90-151 Lodz, Poland
In our study, we attempted to assess the differences in metalloproteinase 1 gene expression between AML blasts and normal leukocytes. Metalloproteinases (MMPs) are various proteolytic enzymes that digest different components of the extracellular matrix (ECM). MMPs participate in many physiological and pathological processes such as embryogenesis, wound healing, inflammation and carcinogenesis. Evidence has shown that the inhibition of MMP activity reduces invasive cancer cells. Currently, these enzymes are still being examined as targets in pharmacological trial treatment. The main function of MMPs in carcinogenesis is not limited to the degradation of ECM; they are also able to regulate many signalling pathways in both normal and cancer cells [5]. MMPs can regulate cancer cell proliferation by the cleavage of precursors of some cell membrane binding growth factors, e.g., TGF $\alpha$. Some growth factors are inactivated by specific proteins such as IGF$\mathrm{BP}$, and MMPs are able to break this connection and stimulate uncontrolled cell proliferation [6]. This group of enzymes may indirectly control cell proliferation by integrins. MMPs can inhibit the growth of cancer cells by activating TGF- $\beta$ [7]. MMPs can regulate apoptosis by cleaving Fas ligand and thus making cells insensitive to apoptotic signals. However, they have both apoptotic and anti-apoptotic features [6]. MMPs are also involved positively in angiogenesis, and much evidence 
shows that inhibitors of MMPs reduce angiogenesis. However, through their ability to degrade some components of the ECM or plasminogen, MMPs generate angiostatin or endostatin, which decrease endothelial cell proliferation. In addition, there is a clear role of MMPs in invasion and metastasis. Cancer cells must secrete many different types of MMPs to degrade the ECM and cross the epithelial basement membrane. Due to these processes, cells enter blood or lymphatic vessels [5, 8]. MMPs are also able to modulate the immune response to cancer by suppressing $\mathrm{T}$ lymphocyte proliferation. This broad participation of MMPs in cancer development is currently targeted in anticancer therapy, but MMP targeting is still not used as standard therapy [6].

The first member of the MMPs group is MMP1. This enzyme is produced in two forms of different glycosylated proenzymes, $52 \mathrm{kDa}$ and $57 \mathrm{kDa}$. The molecular masses of the active forms are $42 \mathrm{kDa}$ and $47 \mathrm{kDa}$, respectively. The human gene for $M M P 1$ is located on chromosome $11 \mathrm{q} 22.2-$ 22.3 [9]. MMP1 gene expression is mainly controlled at the levels of transcription and mRNA stability. Cytokines that increase the transcriptional level of $M M P 1$ include fibroblast growth factor, epidermal growth factor, macrophage colony-stimulating factor, transforming growth factor and interferon $\beta$ and $\gamma$. On the other hand, all-trans retinoic acid and transforming growth factor $\beta$ suppress $M M P 1$ transcription [9]. The participation of different MMPs in solid tumour progression, such as gastric [10], melanoma [11], and breast cancer [12], has been widely proven and confirmed in numerous studies, but in haematological malignance, the role of these enzymes seems to be underestimated. Some evidence shows the contribution of MMP2 and MMP9 in these diseases. In this work, we attempted the assessment of the transcriptional level of $M M P 1$ in patients with AML and compared these results with those of healthy individuals.

\section{Materials and methods}

\section{Materials}

In this study, 32 samples of whole blood taken from patients suffering from AML were used: 18 males and 14 females, median age 58 (range 20-81). The control group consisted of 41 donors without cancer disease, median age 37 (range 26-69). Material from AML patients was collected after diagnosis; samples from healthy donors originated from residue after routine control tests.

\section{Methods}

\section{RNA isolation}

RNA was isolated from whole blood samples by a Total RNA Prep Plus Minicolumn Kit (A\&A Biotechnology, Poland) according to the manufacturer's protocol. After isolation, the concentration of RNA was measured spectrophotometrically. The concentration in all samples derived from patients suffering from AML was adjusted to $0.05 \mu \mathrm{g} / \mu \mathrm{l}$. In the control group, the RNA concentration was adjusted to $0.008 \mu \mathrm{g} / \mu \mathrm{l}$.

\section{Reverse transcription}

A reverse transcription reaction was performed on samples obtained from patients with AML and healthy donors using a High-Capacity cDNA Reverse Transcription Kit (Thermofisher Scientific, USA). The final concentration of RNA in AML samples was $0.05 \mu \mathrm{g} / \mu \mathrm{l}$, and that in the control group samples was $0.008 \mu \mathrm{g} / \mu \mathrm{l}$. The difference in the concentrations of the two groups was a result of a high dissimilarity in patients' leukocytosis.

\section{PCR amplification}

Qualitative assessment of the obtained cDNA was performed by means of PCR amplification of a housekeeping gene $(G A P D H)$ and of the MMP1 gene by JumpStart ${ }^{\mathrm{TM}}$ Taq DNA Polymerase (Sigma-Aldrich, USA). The components of the PCRs for both genes were the same: $0.7 \mu \mathrm{l}$ of each primer at a concentration of $10 \mu \mathrm{M}$ for GAPDH (forward TGGTAT CGTGGAAGGACTCATGAC, reverse ATGCCAGTGAGC TTCCCGTTCAGC) and for MMPl (forward AAAGGG AATAAGTACTGGGC, reverse CAGTGTTTTCCTCAG AAAGAG); $3.5 \mu$ of $10 \times$ PCR buffer without $\mathrm{MgCl}_{2}, 0.7 \mu \mathrm{l}$ of $25 \mathrm{mM}$ magnesium chloride solution, $0.2 \mu \mathrm{l}$ of $2.5 \mathrm{U} / \mu \mathrm{l}$ DNA polymerase, $0.4 \mu \mathrm{l}$ of $2 \mathrm{mM}$ deoxynucleotide mix, and $1 \mu \mathrm{l}$ of template. PCR products were separated by agarose gel electrophoresis to assess the quality of cDNA.

\section{Real-time PCR}

Real-time analysis was performed for the reference and investigated genes on a Stratagene Mx3000P (Agilent Technologies, Germany). The reaction mixture contained $10 \mu \mathrm{l}$ $2 \times$ Biotool $^{\mathrm{TM}}$ SYBR Green qPCR Master Mix, $0.7 \mu \mathrm{l}$ of a $10 \mu \mathrm{M}$ solution of each primer specific for the examined genes, $0.4 \mu \mathrm{l}$ of $50 \times$ ROX Reference Dye 2, $7.2 \mu \mathrm{l}$ of distilled water and $1 \mu \mathrm{l}$ of template. Each sample was amplified in triplicate, and the final result was an average of all $\mathrm{C}_{\mathrm{t}}$ values. To all experiments, a negative control without template was also added in triplicate. The real-time PCR was as follows: $10 \mathrm{~min} 95^{\circ} \mathrm{C}$ primary denaturation, 40 cycles of $95{ }^{\circ} \mathrm{C}$ for $30 \mathrm{~s}, 58^{\circ} \mathrm{C}$ for $1 \mathrm{~min}$ and $72{ }^{\circ} \mathrm{C}$ for $1 \mathrm{~min}$. The specificity of the PCR product was verified on the melting curve. The calculated efficiency was $100 \%$ for the reference gene and $96.5 \%$ for the investigated gene (MMPl). Because the efficiency for the investigated and reference gene was 
different (by approximately 3.5\%), the Pfaffl method was selected to calculate the relative gene expression level.

\section{Statistical analysis}

Statistical analysis was performed using the Statistica 13.1. (StatSoft, Inc., Tulsa, OK, USA). Verification of numerical data with normal distribution was done using the Shapiro-Wilk test. To analyse the homogeneity of variance, the Levene test was used, and to analyse the correlation in the relative gene expression levels, the T-test or the Mann-Whitney $U$ test was used. In all statistical tests used, the p-value was established at 0.05 .

\section{Results}

Qualitative analysis showed the expression of $G A P D H$ (reference) and MMP1 (investigated gene) in all cases. All 73 blood samples of patients with AML and healthy donors were successfully analysed in the next step for relative expression level. GAPDH was used as a reference gene (housekeeping) for comparative analysis event that Handschuh et al. showed by boutique array analysis overexpression of this gene in M2 subtype of AML (group of 22 patients) [13]. It could be a limitation but expression level is also differentiated in physiology and according to scientific agreement was assumed that the level is constant and for qualitative analysis such model is commonly used.

\section{Comparison of relative MMP1 expression ratios in acute myeloid patients and the control group}

Comparative analysis of the relative expression of the MMP1 gene in AML patients and healthy individuals was performed. The difference in the relative $M M P 1$ gene expression level was statistically significant $(\mathrm{p}=0.0000)$. The relative $M M P 1$ expression level in AML patients was lower than in healthy individuals (Fig. 1).

\section{Comparison of the correlation of MMP1 expression with age and gender in acute myeloid patients and the control group}

Next, the association between clinical parameters and MMP1 expression level was examined. First, analysis of relative $M M P 1$ gene expression level and gender did not show any significant differences between the control group $(\mathrm{p}=0.9874)$ and acute myeloid patients group $(\mathrm{p}=0.9843)$. Subsequently, the correlation between age and relative $M M P 1$ gene expression level was examined. No correlation between age and relative $M M P 1$ gene expression ratio was found in either the control group (Fig. 2) or the AML group (Fig. 3).
Fig. 1 Relative $M M P 1$ gene expression level in patients with AML and the control group, the comparison was done according to Mann-Whitney U test, relative $M M P 1$ expression level was statistical significant lower in acute myeloid leukemia patients than in control group $(\mathrm{p}=0.0000)$

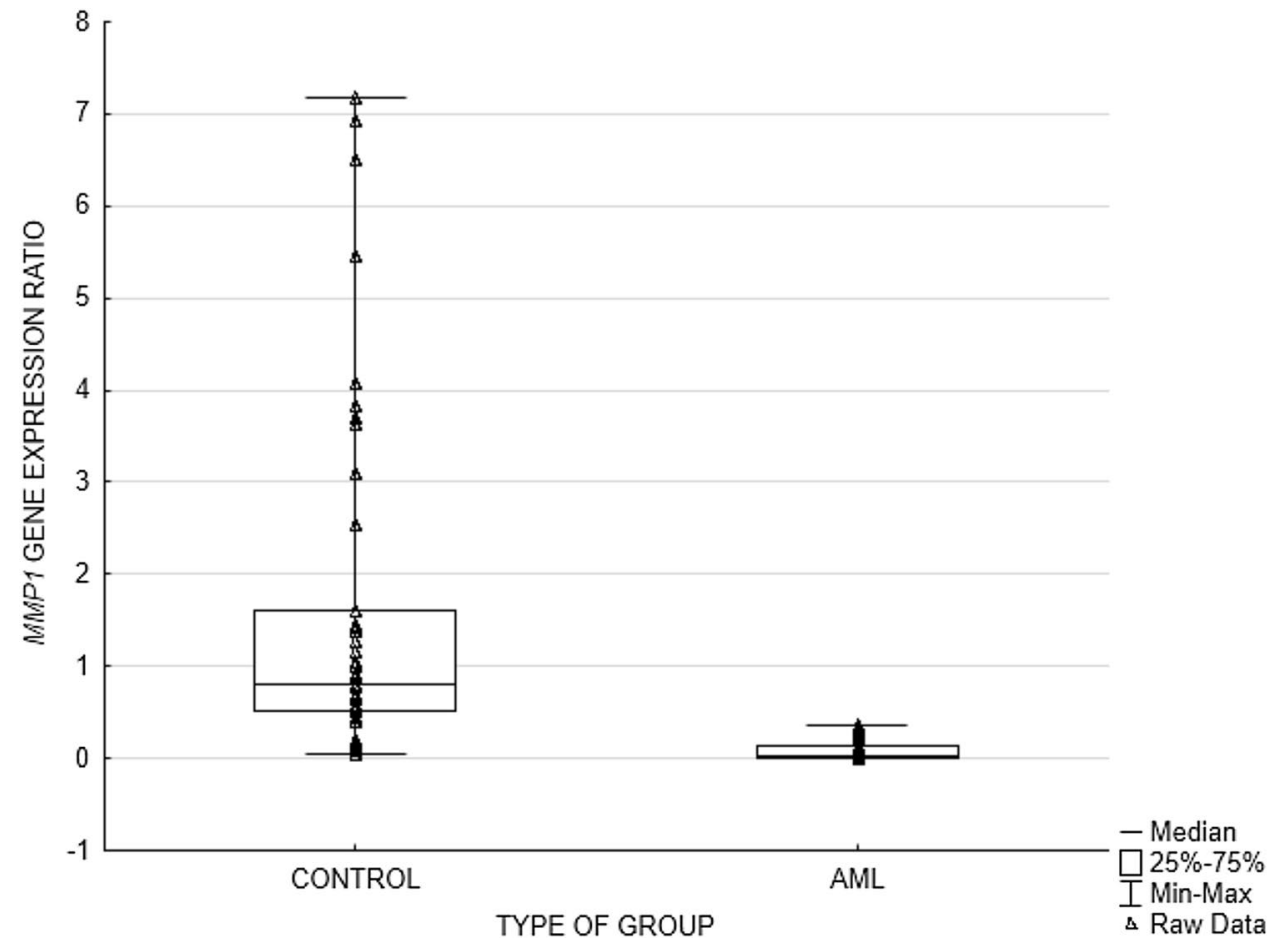




\section{Association of relative MMP1 expression to changes occurring in the karyotype of leukaemic cells and response to first induction therapy}

Next, the association between changes in karyotype and relative $M M P 1$ gene expression ratio was checked. Patients were divided into two groups: the first included patients with changes in karyotype and the second, those with normal karyotype. Statistical analysis did not show any differences in relative $M M P 1$ gene expression between these two groups $(\mathrm{p}=0.8149)$. For a subgroup of patients, clinical information about the first induction therapy was available. These
Fig. 2 Relative $M M P 1$ gene expression level in AML patients according to age, no statistical significant correlation between age and relative MMP1 expression level in AML patients group

Fig. 3 Relative $M M P 1$ gene expression level in the control group according to age, no statistical significant correlation between age and relative MMP1 expression level in the control group
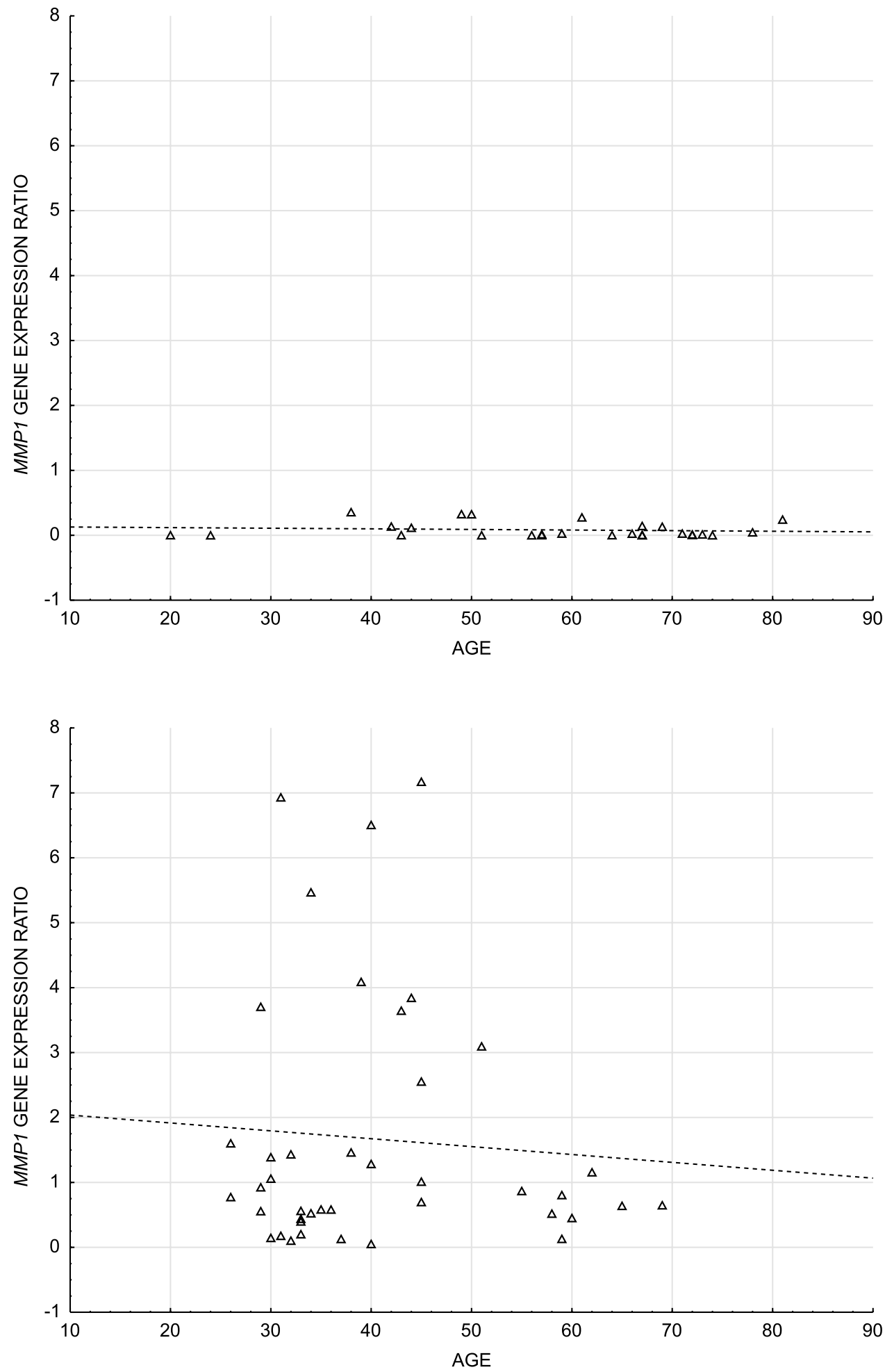
patients were divided into two groups: those with complete remission (nine cases) and those without response to induction chemotherapy (nine cases). There was no significant difference in relative $M M P 1$ expression level between these two groups $(\mathrm{p}=0.1577)$.

\section{Discussion}

The present study demonstrates that the relative $M M P 1$ gene expression in peripheral blood leukocytes is decreased in patients with AML in comparison to that in healthy individuals. The expression of the MMPl gene is regulated by numerous transcriptional factors. The promoter of the $M M P 1$ gene contains a few sites where regulation of gene expression occurs. The first is the AP-1 binding site, which is the main regulation point of $M M P 1$ gene expression level. Two AP-1 binding sites are present in the promoter of the $M M P 1$ gene. Many factors such as MAPK, ERK 1 and 2, JNK, and p38 stimulate expression of the $M M P 1$ gene by inducing the secretion of the AP-1 transcription factor [14, 15]. The results presented in this work show that leukaemia cells in patients with AML have lower MMP1 gene expression levels than normal leukocytes.

Previous studies have primarily shown significant roles of MMP2 and MMP9 in the development of leukaemic clones. These enzymes are other members of the MMP family and are classified to the gelatinase subgroup. In solid tumours, increased concentrations of both proteases are observed in malignant cancers in contrast to benign cancers. In haematological malignance, the role of these proteolytic enzymes seems to be different than in solid tumours [16]. The role of MMP2 in acute myeloid blast development is significant, and high expression of MMP2 correlates with invasiveness of leukaemic cells and drug resistance $[17,18]$. However, the role of MMP9 in AML is different. In contrast to solid cancers, in patients with AML, decreased MMP9 concentration relative to normal controls was observed. In patients with complete remission, the MMP9 amount is similar to that in healthy individuals, but falls in relapse. In addition, higher MMP9 concentrations are correlated with longer overall survival [16]. Therefore, regulation of MMP expression might be different in solid cancers and haematological malignance. This study did not show a statistically significant correlation between response to first induction therapy and relative $M M P 1$ expression. However, this result could be due to too few cases in the examined group. This research project should be continued with a larger group. The role of MMP1 in AML could be different, similar to that of MMP9; some evidence shows that MMP1 inhibits MDS cell proliferation. An analysis of MMP1 mRNA in mesenchymal stem cells showed that MSCs derived from MDS had a lower expression of MMP1 than normal MSCs. This experiment also showed that addition of the MMP1 inhibitor, FN439, into the cell culture caused a significantly increased proportion of cells in S phase. Furthermore, addition of active MMP1 into the cell culture inhibited proliferation and increased the apoptosis of MDS cells. The authors suggested a possible activation of the protease-activated receptor 1 (PAR1) receptor by active MMP1 [19]. The role of the PAR1 receptor in the development of AML is not clear; some evidence shows that activation of the PAR1 receptor inhibits AML cell proliferation but also enhances leukaemic stem cell activity. Deficiency of the PAR1 receptor on the surface of acute myeloid cells causes impaired interaction between leukaemic cells and the surrounding niche. Therefore, activation of the PAR1 receptor could also support the development of leukaemic stem cells [20]. The ability of MMP1 to activate the PAR1 receptor significantly impacts the development of acute myeloid cells. Initial activation of the PAR1 receptor arrests the cell cycle without causing apoptosis but also supports the survival and growth of leukaemic stem cells. Therefore, further study of the role of MMP1 in the development of AML is essential. In particular, knowledge about the role of MMP1 in leukaemic stem cells could positively impact the treatment of minimal residual disease.

This study shows that cancer cells in AML produce less MMP1 mRNA than normal cells and suggests that the role of MMP1 in AML could be different than in solid tumours. The role of MMPs in cancer development is significant. Most evidence shows a greater concentration of MMPs in cancer than under normal conditions. Our study shows a decrease in mRNA expression of MMP1 in leukocytes of patients with AML. The results of our study should be confirmed at the protein level. Another important problem is the estimation of MMP1 in the serum of patients with AML. Some evidence shows that cancer cells are not the main source of MMPs in the serum of patients with cancer, but they secrete cytokines and growth factors that induce other cells to secrete MMPs [21]. Study of the role of MMP1 in the development of AML should be continued, especially for its possible role in the growth of leukaemic stem cells.

Acknowledgements This study was supported by Funds from the Department of Pharmaceutical Biochemistry and Molecular Diagnostics Medical University of Lodz, 503/3-015-02/503-31-001, and Funds from the Faculty of Pharmacy for Young Scientists, Medical University of Lodz, 502-03/3-015-02/502-34-083.

\section{Compliance with ethical standards}

Conflict of interest The authors declare no conflicts of interest.

Informed consent This study was approved by the Bioethical Commission of the Medical University of Lodz: RNN/102/16KE. All patients provided written informed consent before their inclusion in the study. 
OpenAccess This article is distributed under the terms of the Creative Commons Attribution 4.0 International License (http://creativeco mmons.org/licenses/by/4.0/), which permits unrestricted use, distribution, and reproduction in any medium, provided you give appropriate credit to the original author(s) and the source, provide a link to the Creative Commons license, and indicate if changes were made.

\section{References}

1. Estey E, Döhner H (2006) Acute myeloid leukaemia. Lancet 368(9550):1894-1907. https://doi.org/10.1016/S0140 $-6736(06) 69780-8$

2. Buss EC, Ho AD (2011) Leukemia stem cells. Int J Cancer 129(10):2328-2336. https://doi.org/10.1002/ijc.26318

3. Rubnitz JE, Gibson B, Smith FO (2010) Acute myeloid leukemia. Hematol Oncol Clin N Am 24(1):35-63. https://doi.org/10.1016/j. hoc.2009.11.008

4. Kavianpour M, Ahmadzadeh A, Shahrabi S, Saki N (2016) Significance of oncogenes and tumor suppressor genes in AML prognosis. Tumour Biol 37(8):10041-10052. https://doi.org/10.1007/ s13277-016-5067-1

5. Kessenbrock K, Plaks V, Werb Z (2010) Matrix metalloproteinases: regulators of the tumor microenvironment. Cell 141(1):5267. https://doi.org/10.1016/j.cell.2010.03.015

6. Gialeli C, Theocharis AD, Karamanos NK (2011) Roles of matrix metalloproteinases in cancer progression and their pharmacological targeting. FEBS J 278(1):16-27. https://doi.org/10.111 1/j.1742-4658.2010.07919.x

7. Yadav L, Puri N, Rastogi V, Satpute P, Ahmad R, Kaur G (2014) Matrix metalloproteinases and cancer-roles in threat and therapy. Asian Pac J Cancer Prev 15(3):1085-1091. https://doi. org/10.7314/APJCP.2014.15.3.1085

8. Egeblad M, Werb Z (2002) New functions for the matrix metalloproteinases in cancer progression. Nat Rev Cancer 2(3):161-174. https://doi.org/10.1038/nrc745

9. Pardo A, Selman M (2005) MMP-1: the elder of the family. Int J Biochem Cell Biol 37(2):283-288. https://doi.org/10.1016/j.bioce 1.2004.06.017

10. Shen W, Xi H, Wei B, Chen L (2014) The prognostic role of matrix metalloproteinase 2 in gastric cancer: a systematic review with meta-analysis. J Cancer Res Clin Oncol 140(6):1003-1009. https://doi.org/10.1007/s00432-014-1630-6

11. Moro N, Mauch C, Zigrino P (2014) Metalloproteinases in melanoma. Eur J Cell Biol 93(1-2):23-29. https://doi.org/10.1016/j. ejcb.2014.01.002

12. Radisky ES, Radisky DC (2015) Matrix metalloproteinases as breast cancer drivers and therapeutic targets. Front Biosci (Landmark Ed) 20:1144-1163
13. Handschuh L, Kazmierczak M, Milewski MC, Goralski M, Luczak M, Wojtaszewska M, Uszczynska-Ratajczak B, Lewandowski K, Komarnicki M, Figlerowicz M (2018) Gene expression profiling of acute myeloid leukemia samples from adult patients with AML-M1 and -M2 through boutique microarrays, real-time PCR and droplet digital PCR. Int J Oncol 52(3):656-678. https://doi. org/10.3892/ijo.2017.4233

14. Ala-aho R, Kahari VM (2005) Collagenases in cancer. Biochimie 87(3-4):273-286. https://doi.org/10.1016/j.biochi.2004.12.009

15. Vincenti MP, Brinckerhoff CE (2002) Transcriptional regulation of collagenase (MMP-1, MMP-13) genes in arthritis: integration of complex signaling pathways for the recruitment of gene-specific transcription factors. Arthritis Res 4(3):157-164. https://doi. org/10.1186/ar401

16. Klein G, Vellenga E, Fraaije MW, Kamps WA, De Bont ES (2004) The possible role of matrix metalloproteinase (MMP)-2 and MMP-9 in cancer, eg acute leukemia. Crit Rev Oncol Hematol 50(2):87-100. https://doi.org/10.1016/S1040-8428(03)00227-0

17. Song JH, Kim SH, Cho D, Lee IK, Kim HJ, Kim TS (2009) Enhanced invasiveness of drug-resistant acute myeloid leukemia cells through increased expression of matrix metalloproteinase-2. Int J Cancer 125(5):1074-1081. https://doi.org/10.1002/ijc.24386

18. Lin LI, Lin DT, Chang CJ, Lee CY, Tang JL, Tien HF (2002) Marrow matrix metalloproteinases (MMPs) and tissue inhibitors of MMP in acute leukaemia: potential role of MMP-9 as a surrogate marker to monitor leukaemic status in patients with acute myelogenous leukaemia. Br J Haematol 117(4):835-841. https:// doi.org/10.1046/j.1365-2141.2002.03510.x

19. Zhao S, Zhao Y, Guo J, Fei C, Zheng Q, Li X, Chang C (2017) Downregulation of MMP1 in MDS-derived mesenchymal stromal cells reduces the capacity to restrict MDS cell proliferation. Sci Rep 7:43849. https://doi.org/10.1038/srep43849

20. Goyama S, Shrestha M, Schibler J, Rosenfeldt L, Miller W, O’Brien E, Mizukawa B, Kitamura T, Palumbo JS, Mulloy JC (2017) Protease-activated receptor-1 inhibits proliferation but enhances leukemia stem cell activity in acute myeloid leukemia. Oncogene 36(18):2589-2598. https://doi.org/10.1038/ onc. 2016.416

21. Noel A, Jost M, Maquoi E (2008) Matrix metalloproteinases at cancer tumor-host interface. Semin Cell Dev Biol 19(1):52-60. https://doi.org/10.1016/j.semcdb.2007.05.011

Publisher's Note Springer Nature remains neutral with regard to jurisdictional claims in published maps and institutional affiliations. 